\title{
Histiocytic necrotizing lymphadenitis
}

\author{
Takayuki Shirakusa, ${ }^{1}$ Tadaaki Eimoto ${ }^{2}$ and Masahiro Kikuchi ${ }^{2}$ \\ ${ }^{1}$ Division of Thoracic Surgery, Second Department of Surgery and ${ }^{2}$ Department of Pathology, School of \\ Medicine, Fukuoka University, 45-1, Nanakuma, Jyonanku, Fukuoka, 814-01, Japan.
}

\begin{abstract}
Summary: Eleven cases of histiocytic necrotizing lymphadenitis were studied. Originally four were misdiagnosed as cervical tuberculous lymphadenitis. The characteristic symptoms and signs were local tenderness, fever, leucocytopenia and good prognosis. Antibody to Epstein-Barr virus was elevated in 2 of 3 cases. Biopsy of the affected lymph node was necessary when the differential diagnosis from lymph node tuberculosis or malignant lymphoma could not be made. The characteristic histological feature was focal necrosis without neutrophil infiltration in cortical or subcortical areas. Ultrastructurally, we found characteristic inclusions ('tubulo-reticular structures') in histiocytes and lymphocytes.
\end{abstract}

\section{Introduction}

Histiocytic necrotizing lymphadenitis (HNL) was first described by Kikuchi in $1972,{ }^{1}$ who reported 28 cases of lymphadenitis showing focal reticulum cell hyperplasia with nuclear debris and phagocytes. In the same year, Fujimoto et al. ${ }^{2}$ reported the same disease as subacute necrotizing lymphadenitis. Although HNL or subacute necrotizing lymphadenitis is not rare in Japan, there are few reports in Western countries. ${ }^{3}$

We report the clinical features of 11 cases of HNL and findings in light and electron microscopic examination. The differentiation from other diseases, especially tuberculous lymphadenitis is discussed.

\section{Materials and methods}

Of 122 patients who underwent diagnostic lymph node biopsy in the past 5 years, 11 showed the histological features of HNL. Clinical records and laboratory data were reviewed. All of the biopsied nodes were stained with haematoxylin and eosin. Specimens of two patients were fixed in $2.5 \%$ glutaraldehyde and then $1 \%$ osmium tetroxide. After embedding in Epon, ultrathin sections were made, and those were observed with a JEM 100-C transmission electron microscope.

Correspondence: T. Shirakusa, M.D.

Accepted: 9 September 1987

\section{Results}

\section{Clinical findings}

The clinical data are presented in Table I. Eight of the 11 patients were female. The ages ranged from 16 to 41 years with a mean of 27 years.

The enlarged nodes were confined to the cervical region except for one patient (case 6). Six showed unilateral and 4 bilateral cervical lesions. Lymph node enlargement was always multiple. Most patients complained of local tenderness in the initial stage of lymph node swelling. Pyrexia over $38^{\circ} \mathrm{C}$, and leucocytopenia of less than $4 \times 10^{9} / 1$ were found in 6 cases. In 5 of 9 patients, the peripheral blood showed neutrophils below $50 \%$. The erythrocyte sedimentation rate (ESR), examined in 8 patients, was moderately elevated in 2 and considerably in 3 . Toxoplasma antibody titres were examined in 9 and were within the normal range in 8 patients and raised in one case. Antibodies against Epstein-Barr virus were examined in 3 patients; two showed elevated titres of IgM VCM $(\times 320$ and $\times 1280)$. Of the 5 who underwent the Mantoux test, 3 were positive.

The clinical course and prognosis were good in all 11 patients. Corticosteroids were administered to one patient, who showed an excellent response. In 5 patients antibiotics, and in 3 antituberculous drugs were used without clinical effect. The entire clinical course, until complete spontaneous resolution, lasted from 1 month to 6 months.

\section{Histopathology}

Under light microscopy, the typical morphological

(C) The Fellowship of Postgraduate Medicine, 1988 
Table I Clinical findings of 11 cases with histiocytic necrotizing lymphadenitis

\begin{tabular}{|c|c|c|c|c|c|c|c|c|c|c|}
\hline Case & Sex & Age & $\begin{array}{c}\text { Original } \\
\text { diagnosis }\end{array}$ & $\begin{array}{l}\text { Swelling of } \\
\text { cervical } \\
\text { lymph node }\end{array}$ & $\begin{array}{c}\text { Local } \\
\text { pain }\end{array}$ & Fever & $\begin{array}{c}\text { Days from } \\
\text { onset to } \\
\text { biopsy }\end{array}$ & $\begin{array}{c}W B C \\
\left(\times 10^{9} / 1\right)\end{array}$ & $\begin{array}{c}(\% \\
\text { neutro- } \\
\text { phils })\end{array}$ & $\begin{array}{l}E S R \\
(1 h)\end{array}$ \\
\hline 1 & F & 29 & TB & bilateral & + & $38^{\circ} \mathrm{C}$ & 20 & 2000 & 43 & ND \\
\hline 2 & F & 20 & TB & unilateral & - & - & 30 & 3000 & 44 & 8 \\
\hline 3 & F & 32 & PUO & unilateral & + & $38^{\circ} \mathrm{C}$ & 30 & 6800 & 64 & 4 \\
\hline 4 & $\mathbf{M}$ & 17 & Viral LA & bilateral & + & $39^{\circ} \mathrm{C}$ & 90 & 6200 & 62 & 48 \\
\hline 5 & $\mathbf{M}$ & 26 & Neck tumour & unilateral & + & - & 14 & ND & ND & ND \\
\hline 6 & $\mathbf{F}$ & 41 & Axillary LA & $\begin{array}{r}\text { unilateral } \\
\text { (axilla) }\end{array}$ & + & $38^{\circ} \mathrm{C}$ & 50 & 1900 & 64 & 35 \\
\hline 7 & $\mathbf{M}$ & 29 & Viral LA & unilateral & + & - & 5 & 6100 & 48 & ND \\
\hline 8 & $\mathbf{F}$ & 31 & TB & bilateral & - & - & 7 & 5000 & 58 & ND \\
\hline 9 & $\mathrm{~F}$ & 35 & TB & unilateral & + & - & 40 & 3200 & 32 & 13 \\
\hline 10 & $\mathbf{F}$ & 18 & Viral LA & unilateral & + & $39^{\circ} \mathrm{C}$ & 14 & 2800 & 40 & 18 \\
\hline 11 & $\mathbf{F}$ & 18 & Viral LA & bilateral & + & $38^{\circ} \mathrm{C}$ & 120 & 2700 & ND & 55 \\
\hline
\end{tabular}

TB: tuberculous lymphadenitis; WBC: white blood cell; ESR: erythrocyte sedimentation rate; PUO: pyrexia of unknown origin; ND: not done; LA: lymphadenitis.

feature is focal necrosis in the paracortical and/or cortical regions of the affected lymph nodes (Figure 1). The lesions were sometimes single and sometimes multiple. In the areas of necrosis, proliferation of histiocytes with phagocytic activity and large transformed lymphocytes were prominent. Free and phagocytized nuclear debris and cell fragments were found frequently in the centre of lesions. Neutrophil infiltration was rare. Plasma cells were occasionally found.

The characteristic ultrastructural findings in HNL are presented in Figures 2, 3 and 4. Various stages of necrosis were observed in the cytoplasm of small lymphocytes. Sometimes the destruction of cytoplasmic membrane and exudation of intracytoplasmic organelles and/or nucleus were noted. The infiltrating macrophages were rich in intracytoplasmic organelles and cell debris. Characteristic inclusions, the so-called 'tubulo-reticular structures'

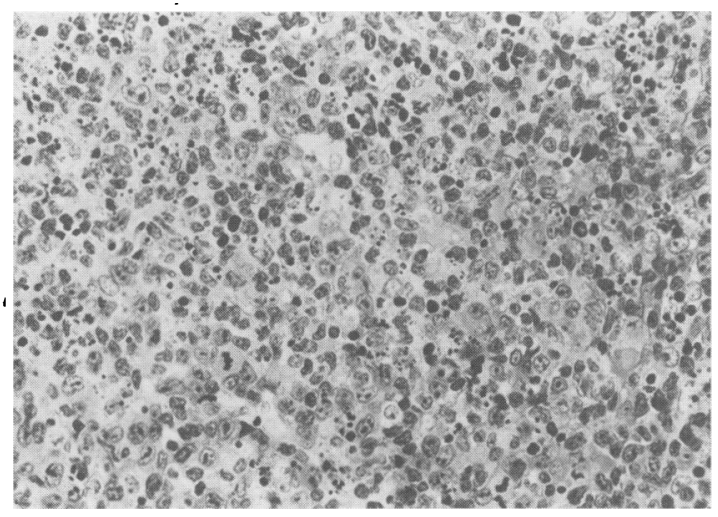

Figure 1 Infiltrating histiocytes and cell debris without neutrophils in a necrotic area. H\&E $\times 240$. were frequent in the cytoplasm of macrophages and small lymphocytes.

\section{Discussion}

Most of the Japanese patients with HNL are young females, whose lesions appear as multiple swellings of lymph nodes in the cervical regions and sometimes in the axillary regions. ${ }^{4}$ Although we have not encountered cases of generalized lymphadenopathy, Pileri in West Germany ${ }^{3}$ reported that 6 of 27 cases had systemic lymph node involvement with fever and leucocytopenia at the time of onset.

Clinically, HNL has been occasionally misdiagnosed as lymph node tuberculosis and treated erroneously before the establishment of the diagnosis by biopsy. Fourteen of 28 cases in Kikuchi's series ${ }^{1}$ and 7 of 12 in Fujimoto's series ${ }^{2}$ had been misdiagnosed as tuberculosis lymphadenitis. Although in advanced stages of lymph node tuberculosis multiple nodes are usually involved, a solitary enlarged node is occasionally seen in the early stage as in HNL. The Mantoux reaction was not useful for the differential diagnosis in our series. Lymph node biopsy may be required to distinguish between tuberculosis, HNL and malignant lymphoma.

HNL differs from abscess-forming lymphadenitis, such as cat-scratch disease, because in the latter, granulocytic infiltration is usually prominent. Pileri $^{3}$ reported that the histiocytes in HNL show prominent phagocytic activity and a strong reaction for lysozyme. Ultrastructurally, one of the characteristic findings is inclusions in histiocytes and lymphocytes called 'tubulo-reticular structures' (TRS). Eimoto et al. ${ }^{6}$ studied these structures in various lymphadenopathies including $\mathrm{HNL}$ and 


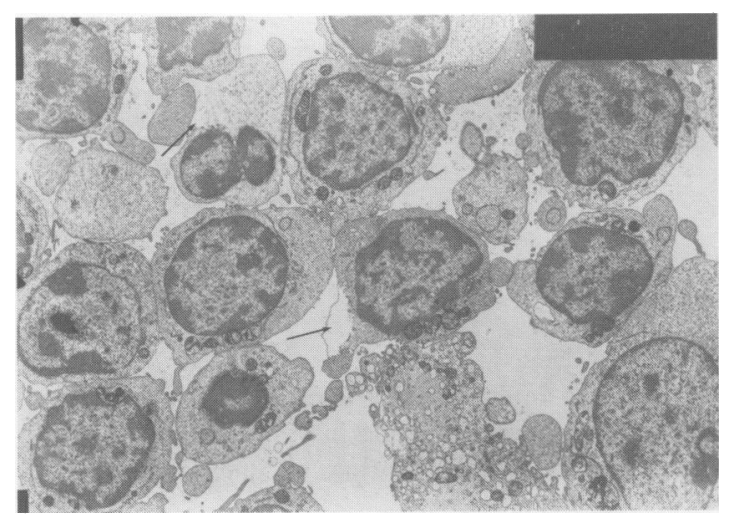

Figure 2 Electron micrograph of small lymphocytes (arrows) showing destruction of cytoplasm in the necrotic lesion; $\times 2000$.

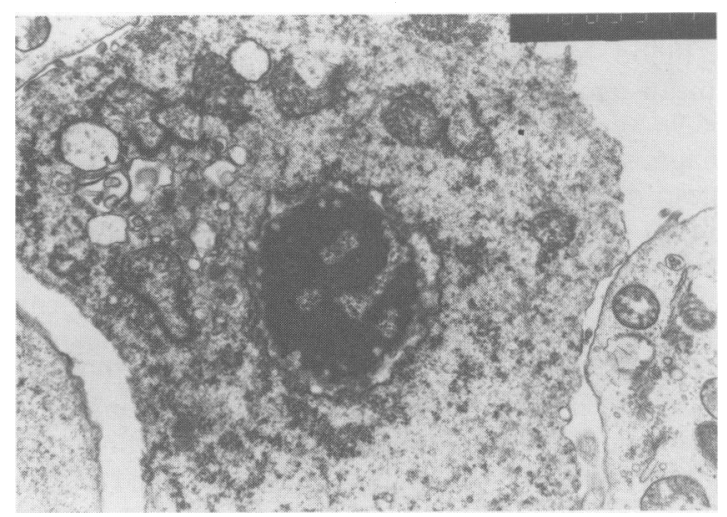

Figure 3 Electron micrograph of a necrotic cell showing disappearance of cell membrane; $\times 10000$

\section{References}

1. Kikuchi, M. Lymphadenitis showing focal reticulum cell hyperplasia with nuclear debris and phagocytes. A clinico-pathological study. Nippon Ketsueki Gakkai Zasshi 1972, 35: 379-380 (in Japanese).

2. Fujimoto, Y., Kojima, Y. \& Yamaguchi, K. Cervical subacute necrotizing lymphadenitis. Naika 1972, 30: 920-927 (in Japanese).

3. Pileri, S., Kikuchi, M., Helbron, D. \& Lennert, K. Histiocytic necrotizing lymphadenitis without granulocytic infiltration. Virchows Archiv A 1982, 395: 257271.

4. Fujimori, T. \& Shioda, K. Subcutaneous necrotizing lymphadenitis - a clinicopathological study. Acta Pathol Jpn 1981, 31: 791-797.

5. Kikuchi, M., Yoshizumi, T. \& Nakamura, H. Is phagocytic necrotizing lymphadenitis acute toxoplasmic infection? Igakunoayumi 1977, 102: 527-529 (in Japanese).

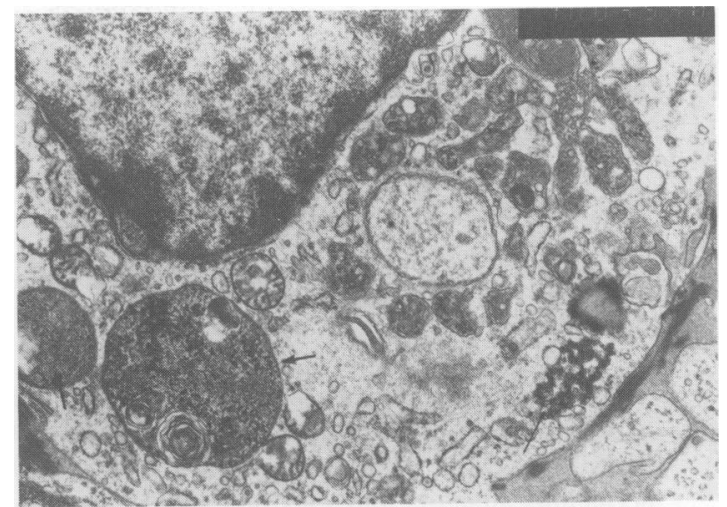

Figure 4 Electron micrograph of a histiocyte with phagocytized cell debris (thick arrows) and characteristic tubuloreticular inclusions (thin arrow); $\times 10000$.

found that the TRS were highly prevalent, though not specific, in HNL in terms of both positive cases and positive cells.

The aetiology of HNL is unclear. Wakasa et al. ${ }^{7}$ postulated that HNL is a subtype of infectious mononucleosis, and Kikuchi et al. ${ }^{5}$ suggested that HNL might be due to toxoplasma infection. Takada et al. $^{8}$ found that antibody to Epstein-Barr virus was elevated in 6 cases, and speculated that HNL was caused by Epstein-Barr virus infection. It is accepted that there is no need to administer specific drugs, because of its excellent prognosis.

\section{Acknowledgement}

The authors acknowledge the great assistance given by Ms Seki and Ms Mitoma, Research Technicians, School of Medicine, Fukuoka University.

6. Eimoto, T., Kikuchi, M. \& Mitsui, T. Histiocytic necrotizing lymphadenitis - an ultrastructural study in comparison with other types of lymphadenitis. Acta Pathol Jpn 1983, 33: 863-879.

7. Wakasa, H., Kimura, H. \& Takahashi, H. Necrotizing lymphadenitis with focal necrotic area. Nipponrinsho 1975, 33: 172-177 (in Japanese).

8. Takada, K. \& Iwanaga, M. Elevated antibody titers to Epstein-Barr virus in subacute necrotizing lymphadenitis. Igakunoayumi 1980, 112: 194-196 (in Japanese). 